\title{
Nilton Campos e a Psicologia Brasileira: Um Resgate Biográfico e
}

\section{Bibliográfico}

\author{
Diego do Nascimento Mendonça* \\ Universidade Federal do Paraná - UFPR, Curitiba, PR, Brasil \\ ORCID: https://orcid.org/0000-0001-8046-9164 \\ Adriano Furtado Holanda** \\ Universidade Federal do Paraná - UFPR, Curitiba, PR, Brasil \\ ORCID: https://orcid.org/0000-0002-7171-644X
}

\begin{abstract}
RESUMO
O presente trabalho centraliza-se no estudo da vida e da obra de Nilton Quadros Campos (1898-1963). Por meio do resgate de parte do legado bibliográfico do psiquiatra brasileiro, bem como de matérias jornalísticas e outras fontes documentais, foi construída uma narrativa biográfica que visa possibilitar uma compreensão de sua trajetória profissional, com subsequente exposição de algumas das principais ideias defendidas em sua obra. À medida que se dedicava aos trabalhos experimentais no Laboratório da Colônia de Psicopatas do Engenho de Dentro e às atividades de docência, crescia sua preocupação com os fundamentos da psicologia, sobretudo no que diz respeito às particularidades dos fenômenos psicológicos. Este posicionamento filosófico explica o encaminhamento que buscou direcionar para a psicologia em nível nacional. Campos defendia a autonomia do objeto psicológico frente às ciências naturais, mas entendia que a nova disciplina não possuía necessidade iminente de emancipação curricular, uma vez que deveria situar-se prioritariamente como campo de fundamentação para as práticas profissionais. Espera-se, assim, poder elucidar o modo de compreensão da ciência psicológica por um importante psiquiatra do século XX, contribuindo, por conseguinte, para a construção da memória da psicologia brasileira.
\end{abstract}

Palavras-chave: Nilton Campos, história da psicologia, psiquiatria, epistemologia.

\section{Nilton Campos and Brazilian Psychology: A Biographical and}

\section{Bibliographic Rescue}

\begin{abstract}
This paper focuses on the study of life and work of Nilton Quadros Campos (1898-1963). Through the rescue of parts of the brazilian psychiatrist's bibliographic legacy, along with journalistic articles and other documentary sources, we aim to build a biographical narrative that will enable an understanding of his professional career, with later exposure of some of main ideas defended in his work. As he was devoted to the experimental work of Laboratory
\end{abstract}

ISSN $1808-4281$ 
of the Colony of Psychopaths of Engenho de Dentro and to teaching activities, the concerns of the brazilian psychiatrist for the fundamentals of psychology grew, especially in regards to particularities of psychological phenomena. This philosophical position explains the direction that he sought to direct to psychology nationally. Campos defended the autonomy of the psychological object in relation to the natural sciences, but he understood that new discipline had no imminent need for curriculum emancipation, since it should be primarily as a theoretical foundation for professional practices. We hope, in this way, to be able to elucidate the way of understanding psychological science by an important psychiatrist of the 20th century, thus contributing to the construction of the memory of Brazilian psychology.

Keywords: Nilton Campos, history of psychology, psychiatry, epistemology.

\section{Nilton Campos y la Psicología Brasileña: Un Rescate Biográfico y}

\section{Bibliográfico}

\section{RESUMEN}

Este trabajo se centra en el estudio de la vida y obra de Nilton Quadros Campos (1898-1963). A través del rescate de parte del legado bibliográfico del psiquiatra brasileño, junto con artículos periodísticos y otras fuentes documentales, construiremos una narración biográfica que permitirá comprender su carrera profesional, con la exposición posterior de algunas de las ideas principales defendidas en su trabajo. Como se dedicó al trabajo experimental del Laboratorio de la Colonia del Psicópatas del Engenho de Dentro y a las actividades de enseñanza, la preocupación del psiquiatra brasileño con los fundamentos de la psicología creció, especialmente con respecto a las particularidades de los fenómenos psicológicos. Esta posición filosófica explica la dirección que el psiquiatra carioca buscó dirigir a la psicología a nivel nacional. Campos defendió la autonomía del objeto psicológico frente a las ciencias naturales, pero entendió que la nueva disciplina no tenía una necesidad inminente de emancipación curricular, ya que debería estar principalmente en el campo de la base de las prácticas profesionales. Esperamos, de esta manera, poder dilucidar la forma de concebir la ciencia psicológica por un importante psiquiatra del siglo $\mathrm{XX}$, contribuyendo así a la construcción de la memoria de la psicología brasileña.

Palabras clave: Nilton Campos, historia de la psicología, psiquiatría, epistemología.

No contexto dos estudos históricos sobre a construção do saber psicológico, verificamos a necessidade de uma reconstituição da trajetória profissional de Nilton Campos (1898-1963) por meio de um resgate historiográfico de sua biografia e bibliografia. Nesta direção, o interesse do psiquiatra brasileiro pela Psicologia relaciona-se diretamente com o projeto de ciência psicológica por ele defendido e que será pormenorizado neste artigo. Dessa maneira, discutiremos o modo de vinculação de Nilton Campos aos estudos em Psicologia, 
elucidando as especificidades de sua carreira; seu protagonismo nos debates em torno da construção de uma ciência psicológica autônoma; e seu legado associado à necessidade de uma fundamentação filosófica para esta nova ciência, em contraposição a perspectivas mais tecnicistas.

Para nossa pesquisa sobre Nilton Campos e sua obra, delimitamos como recorte o período de início de suas atividades laboratoriais, em 1925, até o seu falecimento, em 1963. Apresentaremos, inicialmente, os principais aspectos de sua carreira, especialmente no que diz respeito à sua participação no Laboratório de Psicologia da Colônia de Psicopatas do Engenho de Dentro, no Rio de Janeiro, e à sua ocupação na Cátedra de Psicologia do Curso de Filosofia da antiga Universidade do Brasil (atual Universidade Federal do Rio de Janeiro, UFRJ). Em seguida, buscaremos sintetizar e elucidar algumas das principais ideias presentes em suas produções. Para isso, salientamos que o referido trabalho se constitui, metodologicamente, numa biografia com adicional exposição bibliográfica. Por meio de uma estrutura narrativa crítica e minimamente distanciada de heroísmos e outras supervalorizações (Cruz, 2016), reportar-nos-emos ao psiquiatra carioca a partir do contexto social e temporal no qual ele está inserido.

No que se refere à atuação de Nilton Campos, Penna (1992) estabelecera duas fases distintas: 1) um momento inicial de exercício da Neuropsiquiatria por meio de atividades laboratoriais; e 2) uma fase posterior de maior adesão à pesquisa e à docência. Em nossa pesquisa, entretanto, evidenciaremos que, já na fase inicial de exercício das atividades experimentais, Campos desenvolveu preocupações nitidamente filosóficas em virtude das demandas oriundas de seus trabalhos experimentais e de ensino acadêmico. À medida que se desenvolviam as práticas psicológicas no contexto da época, as reflexões teóricas mostravamse cada vez mais pertinentes. Assim, um diálogo contínuo entre teoria e prática configuravase, para ele, como algo imprescindível para o exercício da Psicologia no país.

Ressaltamos que, por centralizar-se na figura de Nilton Campos e em sua produção intelectual, nosso estudo não possibilitará o detalhamento de lugares e dos demais personagens que serão porventura mencionados, ainda que a relevância de muitos destes tenha se mostrado evidente para outras pesquisas. Salientamos ainda que, no presente trabalho, optamos pela manutenção das citações diretas de Nilton Campos e de outros autores em seu formato original, de acordo com as normas gramaticais e ortográficas então em vigor. 


\section{Carreira e legado de Nilton Campos}

Nilton Quadros Campos nasceu em 23 de agosto de 1898, na cidade do Rio de Janeiro. Era filho de Carmelinda Quadros da Silva Campos e de Luiz Antonio da Silva Campos. Graduou-se pela Faculdade de Medicina do Rio de Janeiro no começo da década de 1920, especializando-se em Psiquiatria (Penna, 1992). Também se diplomou pela Faculdade Nacional de Filosofia, obtendo título de Doutor. Casou-se, em 14 de fevereiro de 1931, com a professora Hilda Higgins Imenes, que o auxiliou na revisão de suas produções textuais (Campos, 1930) e o acompanhou "[...] em toda sua trajetória intelectual, com admirável dedicação" (Penna, 1992, p. 131). Nilton e Hilda não tiveram filhos. Acrescente-se ainda a importante participação de Campos nas atividades do Laboratório de Psicologia da Colônia de Psicopatas do Engenho de Dentro e em demais centros de ensino e pesquisa, como veremos a seguir.

\section{Atuação no Laboratório de Psicologia da Colônia de Psicopatas do Engenho de Dentro}

Nos estudos psicológicos do começo do século XX, destaca-se, na cidade do Rio de Janeiro, o Laboratório de Psicologia da Colônia de Psicopatas do Engenho de Dentro, o qual se consolidou, na década de 1920, como um importante centro de pesquisas laboratoriais. Segundo consta em seus "Annaes", esse espaço destinava-se à profilaxia das "moléstias mentais" por meio do psicólogo como um importante colaborador do médico para essa função (Penna, 1992). O Laboratório foi idealizado pelo psiquiatra Gustavo Riedel (1887-1934) - à época, diretor da Colônia - e, posteriormente, dirigido pelo professor polonês Waclaw Radecki (1887-1953) (Centofanti, 1982; Holanda, 2012; Penna, 1992).

Com predomínio inicial de atividades experimentais, a maximização das atividades do Laboratório de Psicologia da Colônia de Psicopatas deveu-se, sobretudo, à adesão de novos colaboradores. Nessa perspectiva, Nilton Campos foi um "[...] médico-psiquiatra que se entregou de corpo e alma ao estudo da psicologia [...]" (Penna, 1992, p. 32). Sob a orientação do professor Radecki, especializaram-se Nilton Campos e outros médicos interessados em Psicologia (Massimi, 1990; Penna, 1992, 2008).

É notável a importância que o Laboratório teve para o desenvolvimento da Psicologia no país - o que é exemplificado por seus trabalhos realizados em parceria com instituições militares - configurando-se como um grande centro de estudos psicológicos no Brasil (Mancebo, 2008; Penna, 1992) e dispondo de equipamentos trazidos de Paris e da cidade 
alemã de Leipzig: "A localização, apesar de afastada do centro da cidade, prestava-se, contudo pelo seu isolamento, ao trabalho tranquilo da pesquisa experimental" (Campos, 1953, p. 1). Nesse contexto, Nilton Campos integrou o corpo de assistentes do Laboratório e se tornou um dos primeiros profissionais brasileiros a se aprofundar em pesquisas em Psicologia (Holanda, 2012).

O crescimento operacional do Laboratório - aliado ao interesse contínuo por seu aperfeiçoamento e inovação - leva Radecki a chefiar um grupo de médicos em importante viagem profissional à Europa, o que contribuiria para o desenvolvimento da Psicologia no Brasil. Os "Annaes" incluem o relatório dessa viagem ao continente europeu para estudos psicológicos (Penna, 1992). No documento, foram detalhadas as impressões obtidas pelo grupo quanto aos trabalhos desenvolvidos nos centros universitários visitados.

À comissão brasileira chamava atenção o rigoroso processo de formação em Psicologia: “Ao Dr. Nilton Campos coube a responsabilidade de redigir o relatório, de resto, extremamente rico de informações. As cidades visitadas foram: Paris, Bruxelas, Louvain, Colônia, Bonn, Berlim, Varsóvia, Cracóvia, Viena, Munich e Genebra” (Penna, 1992, p. 41). Esta viagem contribuiria substancialmente para o entendimento de Campos quanto à solidez que deveria ser continuamente associada às produções científicas em Psicologia no Brasil, iniciantes à época (Campos, 1953). Com este espírito, o psiquiatra, ao retornar para o Rio de Janeiro, inicia um intenso período de produção acadêmica sobre os fenômenos psicológicos.

Em 1929, publica "Contribuição ao Estudo da Étiopatogenia do Eczema pela Prova Endocrinológica de Parisot e Richard"; e, em 1930, lança o livro "Psychologia da Vida Affectiva", em que aborda o sistema de "discriminacionismo afetivo" de Radecki (Campos, 1930; Penna, 1992). Ao final de sua monografia de seis capítulos, escreve:

Eis-me, finalmente, no mais affectivo de todos os capitulos deste trabalho, porque vaso os meus maiores agradecimentos aos esforços que o Prof. Dr. W. Radecki, director do laboratorio, vem emprehendendo, ha mais de cinco annos, em favor da minha formação e consagração em psychologia, no Brasil e durante a nossa estadia na Europa, culminando no apoio a este ensaio (Campos, 1930, p. 114).

Verifica-se considerável proximidade entre Radecki e seu assistente, embora com momentos de distanciamento entre ambos por razões nem sempre esclarecidas (Penna, 1992). A Campos incumbiu-se a publicação de um elogioso texto em 1953, com finalidade de homenagem póstuma ao seu mestre (Campos, 1953; Penna, 1992, 2008). No necrológio, o 
psiquiatra carioca, ao lembrar-se de seu último encontro com o professor polonês - que se deu no Congresso Internacional de Psicologia de Estocolmo, em 1951 - confessa que, se pudesse estar junto a Radecki em seu derradeiro dia, expressar-lhe-ia "[...] o perene reconhecimento dos colegas brasileiros pela sua inspiração criadora e exemplar fidelidade à ciência da alma [...]" (Campos, 1953, p. 3).

Nesse contexto, o psiquiatra carioca reconheceu a importância da influência do professor polonês em sua formação. Campos exalta a figura de Radecki como um exímio defensor da dignidade da Psicologia, opondo-se a quaisquer formas de violação desta ciência, tais como o emprego de testes sem fundamentos, a mistificação do manejo psicológico e a exploração comercial descontrolada do conhecimento científico.

No começo da década de 1930, Campos viajou para São Paulo e, no Instituto Médicopedagógico Paulista e na Sociedade de Neuropsiquiatria Paulista, pôde contribuir com a fundação destes dois espaços (Penna, 1992). Nesse período, também proferiu discurso de recepção ao Diretor do Instituto de Psicologia da Universidade de Berlim - Wolfgang Köhler (1887-1967) - no Mackenzie College; realizou conferência intitulada “A Psicologia em Face da Psiquiatria, Criminologia e da Pedagogia"; e publicou "Psicologia da Estrutura" no primeiro volume da revista "Política" (Penna, 1992).

Em 1932, o Laboratório vincula-se ao Ministério da Educação e Saúde Pública, convertendo-se num importante instituto (Massimi, 1990). Na ocasião, Nilton Campos ocupa o cargo médico de assistente de Psicologia (Centofanti, 1982; Mancebo, 2008). Em 1935, Campos tornou-se diretor do Serviço Neuropsicológico da Secretaria de Saúde e Assistência a Psicopatas da então capital federal do Rio de Janeiro (Penna, 1992).

Em 1933, Campos participou de um curso de extensão universitária na Universidade do Brasil por meio das "Cinco Conferências sobre a Nova Orientação no Estudo da Vida Afetiva", com destaque para os relatórios psicológicos sobre a infância; e participou também da Conferência de Proteção à Infância através dos trabalhos "Caráter e Personalidade da Criança"; e "O Problema Médico-Pedagógico da Assistência aos Menores Abandonados e Delinqüentes". Em 03 de julho do mesmo ano, participando das atividades da Liga Brasileira de Hygiene Mental, promoveu conferência intitulada "O que se Atribue Injustamente aos Mortos” (“As conferencias”, 1933).

Em 1934, lançou o "Ensaio de Análise Estrutural Somatopsíquica na Esquizofrenia"; e, em 1935, “Os Fundamentos Positivos da Psicologia Moderna”, pelo Boletim da Secretaria de Saúde e Assistência ( $\mathrm{n}^{\text {os }} 2$ e 3, respectivamente). Em 1936, publicou "Projeto do Código Criminal do Brasil e as Ciências Médicas", pelos Arquivos do Manicômio Judiciário (n ${ }^{\text {os }} 1$ e 
2); e "Estado Atual dos Estudos sobre a Etiologia Geral da Epilepsia", pelo Boletim da Secretaria de Saúde e Assistência (n 4) (Penna, 1992).

Em 1937, publicou "Processos Científicos e Pesquisa da Veracidade nos Depoimentos" como resultado de duas conferências realizadas na Sociedade Brasileira de Criminologia. Em 1938, Campos produziu os seguintes trabalhos: "Mentalidade Primitiva" e "Eletroencefalografia", publicados em Ata Médica; "Estados Súbitos de Excitação Psicomotora", via conferência radiofônica no programa Hora Médica do Brasil; além de "As Aquisições da Moderna Psicologia" e "Aspectos da Psicologia", pelo Boletim da Secretaria de Saúde e Assistência" (n ${ }^{\text {os }} 6$ e 7, respectivamente). Em 1940, publicou "Exame Psicológico da Personalidade", pela Revista do IRB ( $n^{\circ}$ 2); e "Fundamentos da Análise Científica da Vida Afetiva”, pelo Anuário Brasileiro de Medicina (Penna, 1992).

Na parte de docência, assinalamos que, ao final da década de 1930, Campos dedicouse ao ensino de Psicologia e Lógica no Colégio Pedro II, atuando também como docente de Psicologia no curso complementar da Faculdade de Medicina e da Escola de Enfermeiras Alfredo Pinto ("Ensino: Faleceu”, 1963b; Penna, 1992). Além disso, participou, em 1938, da inauguração do Instituto de Assistência Médico-Social de Copacabana, espaço voltado para atividades de seleção profissional. Em 09 de novembro de 1939, tomou posse do cargo de professor da Faculdade de Filosofia e Faculdade de Ciências Econômicas.

Salientamos ainda que Campos esteve presente em inúmeras cerimônias acadêmicas ("Ensino: Faleceu", 1963b), como em 1942, quando se responsabilizou pela "Oração de Paraninfo" da turma de licenciados em Filosofia; e em 1943, quando proferiu o "Discurso de Paraninfo" da turma de licenciados do mesmo curso.

\section{Exercício da Cátedra de Psicologia Geral na Universidade do Brasil}

Em 1944, o instituto de estudos em Psicologia foi incorporado à antiga Faculdade Nacional de Filosofia (FNFi), da Universidade do Brasil, cabendo a direção do órgão ao professor Nilton Campos. Além disso, a Cátedra de Psicologia Geral, pertencente à seção de Filosofia, foi oficialmente assumida por Campos mediante defesa da tese "O Método Fenomenológico na Psicologia", naquele que se constituiu o primeiro concurso para o cargo na instituição (Guimarães, 1981; Holanda, 2012). A referida tese foi redigida em 1945 e defendida em 1948 (Penna, 1992). Por questões administrativas, ressalte-se que Campos também assumiu provisoriamente a Cátedra de Psicologia Educacional, pertencente à seção de Pedagogia da FNFi. 
A tese de Nilton Campos é atualmente considerada a primeira grande produção brasileira a aprofundar-se na discussão sobre os possíveis diálogos entre a filosofia fenomenológica e a prática psicológica. Da tese, Campos adaptou o primeiro capítulo para o inglês, Fundamentals of the Phenomenological Atitude in Modern Psychology - em virtude do $12^{\circ}$ Congresso Internacional de Psicologia, realizado em julho de 1948 na cidade de Edimburgo, Escócia - e publicou esta adaptação no Boletim do Instituto de Psicologia, em 1951 (Penna, 1992).

À medida que desenvolveu as atividades institucionais, cresceu a atenção de Campos pelos fundamentos das práticas psicológicas. Sob a atribuição de uma chamada "linha acadêmica" em seus trabalhos (Martins, 2008), entende-se que "suas relações com a psicologia estavam permeadas pelos aspectos filosóficos e, no âmbito científico, pelo prisma metodológico" (Centofanti, 1982, p. 32).

Durante seu período na Cátedra - e por sugestão de seu assistente, o professor Antonio Gomes Penna (1917-2010) - Campos criou o Boletim do Instituto de Psicologia, um periódico voltado para a divulgação de produções acadêmicas. Penna (2008, p. 9) assinala o seguinte: "Quando, em 1951, fui nomeado para o Instituto de Psicologia, sugeri ao Professor Nilton Campos a criação e edição de uma Revista, a que dei o nome de 'Boletim do Instituto de Psicologia"”.

Em 1951, Campos também publica as seguintes obras: “A Influência do Pensamento de Wilhelm Dilthey na Evolução da Psicologia como Ciência Autônoma”; "A Teoria Binária da Percepção"; "A Teoria das Estruturas Isomórficas na Psicologia Fisiológica Gestaltista”; La Legitimité de la Méthode Introspective dans la Psychologie Moderne; "O Modelo Mecanicista do Behaviorismo de Watson"; e "O Problema das Relações entre a Neurologia e a Psicologia”, todos pelo Instituto de Psicologia.

No ano seguinte, pelo Boletim do Instituto de Psicologia, Campos publicou "O Problema da Existência da Realidade Transfenomenal" ( $n^{\text {os }} 7$ e 8); e "O Problema da Autonomia dos Conceitos de Personalidade e de Comportamento, na Pesquisa Psicológica Atual" ( ${ }^{\text {os }} 11$ e 12). Em 1953, foi a vez de "Natureza dos Constructos Hipotéticos Neurológicos Utilizados na Psicologia Científica" ( $n^{\text {os }} 7$ e 8 ); além de "Diferença entre Descrição e Explicação no Estudo da Psicologia Científica" (n ${ }^{\text {os }} 11$ e 12), o qual, ressaltamos, referia-se à comunicação para o Congresso Brasileiro de Psicologia, realizado em dezembro do mesmo ano na cidade de Curitiba, Paraná. Publicou também o já mencionado "Necrológio: Waclaw Radecki (1887-1953)", pelo Boletim. Ainda em 1953, uma edição do Boletim 
publicou um artigo com comentários do professor Köhler acerca do trabalho de Nilton Campos.

No ano de 1954, Campos publicou "Antecedentes Filosóficos do Isomorfismo Gestaltista" ( $\mathrm{n}^{\text {os }} 3$ e 4). Em 1955, "Limitações das Teorias Naturalistas da Personalidade Humana" ( $n^{\text {os }} 1$ e 2); e "Algumas Considerações sôbre a Psicologia Científica do Pensamento" (n ${ }^{\text {os }} 9$ e 10). Posteriormente, publica "Sigmund Freud" (1956, n ${ }^{\text {os }} 5$ e 6); "Humanismo e Economia" (1958, n ${ }^{\text {os }} 3$ e 4); "Importância e Significado da Análise Qualitativa Fenomenológica no Estudo das Ciências Sociais" (1958, n ${ }^{\text {os }} 7$ e 8); "Filosofia e Ciência Positiva" (1959, $\mathrm{n}^{\text {os }} 1$ e 2); "Aspectos Psico-sociais do Problema da Produtividade" (1959, $\mathrm{n}^{\text {os }} 7$ e 8); e “A Ética Através dos Tempos" (1960). Além destes, também publicou “A Teoria Gestaltista de Koehler e as Relações entre a Psicologia e o Evolucionismo".

Campos fez parte da primeira diretoria do Instituto de Filosofia, um espaço que objetivaria “[...] congregar estudiosos e pensadores das mais diversas tendências, com a finalidade de debater problemas filosóficos, ministrar cursos e fazer publicações concernentes à sua especialidade" ("Cursos: Instituto", 1956, p. 10). Lembramos ainda a participação de Campos nos cursos de ética médica, organizados pelo Conselho Regional de Medicina do então Estado da Guanabara; e nas conferências sobre o problema da produtividade no aspecto psicossocial, promovidas pelo Instituto de Ciências Sociais da Universidade do Brasil (Campos \& Lourenço Filho, 1962).

\section{A Marca Filosófica de Nilton Campos e o Embate Acadêmico com Mira y López}

Demonstrando forte apreço pelo ensino de Psicologia em uma faculdade de Filosofia, Campos, no prefácio de sua tese de 1945, justificou e esclareceu o posicionamento metodológico que adotou ao longo de sua carreira:

Meditando sobre os objetivos primordiais do ensino da Psicologia em um curso de filosofia, afastamos desde logo a ideia de um trabalho experimental, pois julgamos que o espírito da cátedra impunha, antes, a escolha de um assunto de natureza não técnica (Campos, 1945, pp. 8).

Como afirmamos anteriormente, estudos teóricos mostravam-se indispensáveis para Campos em meio às demandas oriundas das práticas psicológicas nas instituições brasileiras. Além disso, "assinale-se que as preocupações mais teóricas e filosóficas de Nilton 
encontraram apoio em uma excelente cultura filosófica construída através de uma leitura muito refletida dos grandes pensadores que marcaram a história do pensamento ocidental" (Penna, 1992, p. 136).

As atividades de Campos no Instituto de Psicologia não se restringiram, portanto, a práticas experimentais. Na verdade, sobrepõem-se a estas os trabalhos puramente teóricos acerca da ciência psicológica (Penna, 1992). Destacamos, então, que “[...] o professor Nilton Campos incentivava que os seus professores assistentes estudassem, ministrassem aulas, escrevessem e publicassem as teorizações presentes no campo 'psi' [...]" (Mancebo, 2008, p. 64).

Ao participar da inauguração da seção carioca do Instituto Brasileiro de Filosofia, em 19 de abril de 1956, Nilton Campos, na condição de presidente da nova instituição, discursou sobre a

[...] necessidade da filosofia para a compreensão dos modernos problemas da técnica e da ciência. Sem uma concepção do mundo e da vida, e principalmente sem uma epistemologia prévia, ficariam vazios e sem validade universal os métodos e os critérios empíricos das diferentes ciências (Moraes Filho, 1956, pp. 47).

Na primeira metade do século XX, discutia-se a viabilidade da criação de um curso específico de Psicologia no País, com consequente profissionalização da categoria. Campos posicionava-se como um ferrenho opositor a esta ideia (Jacó-Vilela, 2012), considerando-a precoce para a realidade brasileira; receava, portanto, uma eventual desqualificação da Psicologia científica em âmbito nacional (Martins, 2008).

Campos defendia uma formação curricular criteriosa em Psicologia, vinculada à Medicina. Além dos quatro anos de graduação, o estudante deveria especializar-se por mais dois anos para, somente assim, ter direito ao diploma de psicólogo: "E o meu desejo é que só depois dos seis anos completos, incluída a defesa de tese, venha o direito de exercer uma profissão realmente delicada e mal compreendida. Aliás, o curso já será um estímulo ao amadurecimento" (Campos, 1953 citado por Lobo, 1953, p. 1).

Da mesma forma como o físico não possui a competência necessária para o exercício da Fisioterapia - ou o químico, para a prescrição de medicamentos - Campos entendia que a Psicologia caracterizaria um saber fundamental e auxiliar no tratamento de saúde que - por sua vez - teria o médico como supervisor (Lobo, 1953). Assim, defendia que a criação de um curso para profissionais de Psicologia exigiria bom planejamento e forte base teórica. 
Sabemos que a profissão de psicólogo e os cursos de psicologia foram regulamentados em 27 de agosto de 1962 - pelo então Presidente da República, João Goulart - por meio da Lei $n^{\circ}$ 4.119. Entretanto, ainda em 1953, inicia-se o primeiro curso superior autônomo de Psicologia, na Pontifícia Universidade Católica do Rio de Janeiro (Esch \& Jacó-Vilela, 2012). No mesmo ano, a congregação da Faculdade de Filosofia, Ciências e Letras da Universidade de São Paulo (USP), a partir de proposta de Annita Cabral (1911-1991), aprovou a criação do curso de Psicologia na instituição, embora este tivesse começado a funcionar efetivamente apenas em 1958.

O curso da USP possuía duração de três anos, “[...] tinha caráter predominantemente teórico e acadêmico e não outorgava nenhum direito de natureza profissional, a não ser o de magistério [...]" (Angelini, 2006, p. 103). Em todo caso, Campos não presenciou a criação de um curso de graduação em Psicologia na Universidade do Brasil, instituição onde lecionava.

Como dissemos, Nilton não viveu o tempo necessário para realizar a implantação do curso de Psicologia da Faculdade Nacional de Filosofia. Coube-nos, na verdade, essa honra em 1964 quando, juntamente com o professor Eliezer Schneider, que o substituiu interinamente no Instituto de Psicologia, o organizamos e o pusemos a funcionar, cabendo-nos, ainda, a honra de coordená-lo até 1967, quando ocorreu a extinção da Faculdade Nacional de Filosofia e o curso se transladou para o Instituto de Psicologia (Penna, 1992, pp. 142).

Campos não era um opositor ao estudo da Psicologia no Brasil. Entretanto, o encaminhamento a ser dirigido para a ciência psicológica por ele defendido divergia dos renomados trabalhos do psiquiatra Emilio Mira y López (1896-1964). Contemporâneo de Campos e diretor do Instituto de Seleção e Orientação Profissional - pertencente à Fundação Getúlio Vargas (FGV) - Mira y López gerenciava uma instituição internacionalmente reconhecida por seu importante trabalho de formação de técnicos em Psicologia e que constituía um espaço de apoio para a mobilização científica que reivindicava a regulamentação da profissão no Brasil (Angelini, 2006). Esse cenário favoreceu a compreensão do fato de que "[...] Nilton e Mira y López nunca tiveram boas relações” (Penna, 2008, p. 137). Em raro momento de proximidade, os nomes de ambos constam nos registros da conferência "A Moderna Psicologia a Serviço do Trabalho Profissional" ("A Psicologia”, 1945). 
Campos, por sua vez, defendia a autonomia desta nova disciplina mais a nível de fundamentação do que no âmbito de uma aplicabilidade. Ainda que não vislumbrasse a necessidade iminente de emancipação curricular para a Psicologia, Nilton Campos foi nome de destaque na construção de cursos pioneiros em estudos psicológicos no País (antes da regulamentação da profissão). Somando-se às significativas pesquisas psicológicas efetuadas no Laboratório do Engenho de Dentro, registramos seu apoio à implantação do curso desenvolvido pelo Instituto de Psicologia Aplicada, da Pontifícia Universidade Católica do Rio de Janeiro (PUC-Rio):

O profissional chamado de psicotécnico surge [...] com o objetivo de tornar a produção mais eficiente. No Rio de Janeiro, esse novo profissional ganhou um lugar em 1947, com a vinda para o Brasil de Emílio Mira y López, que passou a ministrar um curso intensivo, com a preocupação prática de oferecer serviços de orientação e seleção profissional, no recém-fundado Instituto de Seleção e Orientação Profissional (ISOP) [...]. Contrapondo-se a esse caráter eminentemente prático, a Psicologia, como disciplina, é ministrada na PUC-Rio [...], e o corpo docente era formado por médicos, filósofos e educadores. Nilton Campos [...] foi um importante colaborador na implantação do curso [...] (Féres-Carneiro, 2011, pp. 147).

Nessa perspectiva, entende-se que: “[...] o professor Campos era defensor de uma Psicologia teórica fortemente embasada nos conhecimentos filosóficos e um ferrenho crítico dos cursos tecnicistas promovidos por Mira y López, no ISOP” (Mancebo, 2008, p. 68). Os trabalhos acadêmicos de Mira y López eram, por sua vez, reconhecidos quanto ao "[...] objetivo de dar a pessoas habilitadas oportunidade de especializarem seus conhecimentos nos diferentes ramos de Psicologia aplicada" (“Ensino: Curso", 1958, p. 4).

Mas Campos também esteve presente em outros espaços. Solicitou, via correspondência pessoal, o apoio do colega Pedro da Silva Nava (1903-1984) para concorrer à vaga de titular na Academia Nacional de Medicina (ANM), no Rio de Janeiro. Na ocasião, candidatou-se por meio do trabalho "Evolução do Problema das Relações entre Alma e Corpo: Sua Permanência nas Investigações Psicológicas e Nevrológicas Atuais" (Penna, 1992). Em 5 de outubro de 1961, Campos foi eleito membro-titular pela mencionada instituição ("Ciência e Cultura”, 1961), ocupando a cadeira de número 59. Além da participação na ANM, Campos integrou diversas entidades nacionais e internacionais. 
O professor Antonio Gomes Penna abordou a contribuição de Campos na primeira edição do Seminário de História da Psicologia, realizado nos dias 11 e 12 de abril de 1988 no Instituto Superior de Estudos e Pesquisas Psicossociais, da Fundação Getúlio Vargas, na cidade do Rio de Janeiro. Em homenagem a Nilton Campos, o pavilhão do curso de Psicologia da UFRJ recebeu oficialmente o nome do psiquiatra carioca, o qual falecera em 9 de setembro de 1963 em decorrência de graves problemas de saúde ("Ensino: Faleceu", 1963b; Penna, 2008). Em seu sepultamento - no cemitério São João Batista, no Rio de Janeiro, e sob a presença de familiares, amigos, alunos, colegas e representantes das instituições nas quais trabalhou - Nilton Campos recebeu “[...] as homenagens que deviam ser tributadas a um homem de grande cultura, caráter e bondade" ("Ensino", 1963a, p. 8).

Em linhas gerais, percebemos que Nilton Campos costumava expressar cautela diante de certas inovações e tendências de sua época (Campos, 1953). Além da já mencionada preocupação com uma eventual desvalorização da Psicologia aplicada, havia sua curiosa inquietação frente ao uso demasiado de aparelhos televisores por crianças. Campos temia um possível comprometimento do desenvolvimento infantil em virtude da competitividade desigual entre os estimulantes programas televisivos e um contexto escolar brasileiro cuja realidade era, para ele, permeada por pouco investimento em infraestrutura e por baixa remuneração de professores. Uma alternativa interessante para essa problemática seria, na visão de Campos, a criação de um canal de televisão com finalidade exclusiva para a educação ("A televisão", 1960).

Note-se que a carreira de Campos foi marcada por constantes atuações institucionais e por vasta produção intelectual, na qual não descartamos a possibilidade de existência de textos inéditos. Na seção seguinte, abordaremos algumas das principais ideias presentes em trabalhos publicados por Nilton Campos, sobretudo no que diz respeito à sua compreensão de ciência psicológica.

\section{A Ciência Psicológica para Nilton Campos}

Já no início de suas produções, Campos demonstra interessar-se pela reflexão sobre aquilo que constituiria problema de investigação para a Psicologia, entendendo que muitas das temáticas para as quais a ciência psicológica se volta encontravam-se preliminarmente no âmbito das reflexões filosóficas. Nesse cenário, a afetividade constituiria um assunto de grande relevância para a Psicologia: 
Todos os problemas da psychologia são velhos, tão velhos quanto a humanidade e, embora a crystallisação do dominio da vida affectiva, como assumpto da sciencia psychologica, seja relativamente recente, nas mais antigas obras escriptas da cultura antiga, encontramos já certas referencias preciosas relativas ao nosso assumpto. (Campos, 1930, pp. 5-6)

Campos entende que o processo afetivo nunca poderá ser analisado de maneira isolada, ou seja, encontra-se em constante relação com algum aspecto externo. Para Campos, o contato com os excitantes sensoriais é fundamental para a ocorrência dos processos afetivos. Tudo isso ofereceria à Psicologia um campo ilimitado de pesquisas. À medida que suas pesquisas experimentais avançavam, o psiquiatra se voltava para os aspectos não orgânicos do sujeito dada a demanda verificada nos próprios estudos experimentais:

As nossas experiencias, dirigidas pelo Prof. Radecki, pertencem, theoricamente, ao grupo das experiencias baseadas na expressão orgânica, porém a technica inclinou-nos a tomar em grande consideração os depoimentos introspectivos dos pacientes para recolher informações que nos permittam poder considerar o excitante como conhecido antes de analysar a sua expressão organica. (Campos, 1930, pp. 108)

Em alusão a essa não determinação biológica, Campos defendia a autonomia epistemológica da Psicologia frente à Neurologia e à própria Psiquiatria, em um contexto histórico em que “[...] o estudo da psicologia era dominado pela psiquiatria, cujo prestígio soberano lhe anulava qualquer possibilidade de posição independente" (Campos, 1953, p. 1).

Além da Neurologia e da Psiquiatria, Campos reconheceu a necessidade de haver diálogos entre a Psicologia e outras áreas do conhecimento, como a Filosofia e as Ciências Sociais. Assim, ele se voltou efetivamente para os estudos filosóficos, evidenciando o seu "[...] profundo amor às coisas do espírito" (Campos, 1943, p. 3). O permanente diálogo entre o pensamento filosófico e a atividade experimental é, para Campos, fundamental para a delimitação do objeto psicológico.

Em seus trabalhos, Campos retomava, constantemente, a discussão acerca dos fundamentos epistemológicos para a ciência psicológica, tais como a Teoria da Gestalt (Campos, 1945). Nas ideias de Köhler, Campos encontra uma notável crítica às teorias nativistas e empiristas, uma vez que ambas não conseguiram produzir explicações satisfatórias acerca de temas psicológicos. 
O psiquiatra carioca entendia a importância de formulações críticas à “[...] existência de locais anatômicos do cérebro fixados para o exercício de funções mentais isoladas" (Campos, 1954, p. 1), pois, em tais considerações, justificar-se-ia a autonomia científica da Psicologia frente à Neurologia e à Psiquiatria. Campos defendia que o estudo dos fenômenos mentais não pode reduzir-se a uma mera dedução de leis fisiológicas, o que marca "a irredutibilidade da psicologia a qualquer outra ciência natural” (Campos, 1954, p. 2).

Assim sendo, o estudioso dos processos do pensamento não está obrigado a falar em têrmos neurológicos, mas suas investigações psicológicas devem ser traduzíveis em fatos neurológicos. Essa preocupação de ordem fisiológica não quer dizer que a neurologia deve substituir a psicologia, porquanto sòmente visa ser um auxílio para a última (Campos, 1955, pp. 9).

Essa visão de Campos, destacamos, associa-se com sua já mencionada defesa por uma autonomia da ciência psicológica mais em âmbito filosófico que estritamente técnico. Ainda que desvinculado do domínio das ciências naturais, o conhecimento psicológico poderia continuar a ser desenvolvido por profissionais como os da Psiquiatria e da Neurologia, tal qual já acontecia na realidade brasileira desde o final do século XIX. Além disso, Campos temia uma desvalorização das práticas psicológicas a partir de uma regulamentação precoce e não criteriosa para o profissional de Psicologia.

\section{Considerações Finais}

Pelo exposto, reconhecemos Nilton Campos como figura de destaque para a construção da ciência psicológica no Brasil. Penna (1992) já havia indicado o perfil de Campos no que diz respeito aos temas psicológicos, entendendo que "[...] a grande motivação de Nilton Campos pelos estudos centrados em temas mais teóricos e filosóficos resultava do fato de estar lecionando Psicologia em um Departamento de Filosofia” (Penna, 1992, p. 136). Em nossa pesquisa, porém, pormenorizamos o percurso de Campos até a Cátedra. Nesse sentido, entendemos que a inclinação de Campos para a discussão de teorias psicológicas se estabeleceu ainda na fase inicial de sua carreira.

Em meio às atividades experimentais em Neurologia e Psiquiatria, Campos iniciou, sob influência de seu mestre Waclaw Radecki, um período de estudo rigoroso dos afetos (Campos, 1930). Assim, verificou a necessidade da incorporação de investigações voltadas 
para os aspectos não orgânicos do sujeito em virtude da compreensão de que os processos cerebrais não abrangeriam a totalidade dos fenômenos mentais. Dessa forma, entendemos claramente que Campos viu a necessidade de estudos teóricos em Psicologia a partir das demandas oriundas das atividades empíricas. Em suas produções, predomina a ideia de que os fenômenos psíquicos não podem ser reduzidos a aspectos neurofisiológicos, ainda que ambos se correlacionem. Nessa direção, aproxima-se de formulações como as do psicólogo alemão Wolfgang Köhler.

Essa notória preocupação com a ciência psicológica cresceu à medida que Campos avançou nos trabalhos teóricos e empíricos. O psiquiatra carioca enfatiza a defesa pelo diálogo constante entre Filosofia e Ciência como fator imprescindível para o desenvolvimento e autonomia destes saberes. Seus textos iniciais explicitam a importância da reflexão filosófica para a fundamentação da prática científica, enfatizando a importância do rigor metodológico na execução e exposição de pesquisas em centros universitários e em demais instituições.

Como exposto, Campos era forte opositor à emancipação da Psicologia à época por entender a necessidade de sólido embasamento teórico que deveria haver previamente para esta ciência. O impacto da defesa de Campos por uma ciência psicológica mais "filosófica" que "técnica" - associada ao embate acadêmico com os trabalhos do psiquiatra Emílio Mira y López - consubstancia-se em um debate que podemos considerar como atual, visto o cenário contemporâneo da ciência psicológica no Brasil. Ambos os pesquisadores almejavam o aprofundamento da Psicologia a nível nacional, mas divergiam quanto ao encaminhamento a ser direcionado para este saber. Uma vez tomada a decisão de contínua revisão dos possíveis lugares para a prática psicológica, julgamos imprescindível o amplo conhecimento das diversas apropriações relativas à ciência psicológica e a seu objeto.

Entendemos, assim, que a ocupação da Cátedra mediante a defesa da tese apenas deu continuidade à postura filosófica que Campos adotara em suas atividades psicológicas no Laboratório de Psicologia da Colônia de Psicopatas do Engenho de Dentro, na década de 1920. Diante de uma ciência recente, Campos refletia que os problemas da Psicologia são “[...] tão velhos quanto a humanidade [...]" (Campos, 1930, p. 5).

Todo esse cenário constrói uma imagem de um pensador que se encontrava comprometido com a ciência psicológica e com a construção deste saber; além de um respeitado pesquisador cujas preocupações acadêmicas, nitidamente relevantes no contexto atual, destacam-no em seu tempo. Nilton Campos constitui, indubitavelmente, “[...] uma das maiores autoridades brasileiras em psicologia” (“Ensino: Faleceu”, 1963b, p. 10). 


\section{Referências}

A Psicologia e o Trabalho Profissional: A conferência, amanhã, do professor Mira y Lopez. (1945, Novembro 6). O Globo, pp. 5.

A televisão educa ou prejudica a criança? Dois conhecidos psicólogos opinam sobre a crescente e marcante influência dos programas de televisão sôbre a infância. (1960, Março 17). O Globo, pp. 3.

Angelini, A. L. (2006). Subsídios para a história da Psicologia no Brasil e a criação do Instituto de Psicologia da USP. In A. L. Angelini (Org.). Memória da Psicologia: Textos produzidos na segunda metade do século XX (pp. 101-111). São Paulo: Vetor.

As conferencias da Liga Brasileira de Hygiene Mental. (1933, Julho 2). A Nação, pp. 5.

Campos, N. \& Lourenço Filho, M. (1962). Produtividade: Aspecto Psico-social. Cadernos de Ciências Sociais. Instituto de Ciências Sociais, Universidade do Brasil. (8), 5-34.

Campos, N. (1930). Psychologia da vida affectiva. Rio de Janeiro: s.n.

Campos, N. (1943). Discurso de paraninfo. Rio de Janeiro, Jornal do Commercio, pp. 3-14.

Campos, N. (1945). O método fenomenológico na Psicologia (Tese de Concurso apresentada à Cátedra). Universidade do Brasil, Rio de Janeiro.

Campos, N. (1953). Necrológio: Waclaw Radecki (1887-1953). Boletim do Instituto de Psicologia. (3-4), 1-3.

Campos, N. (1954). Antecedentes filosóficos do isomorfismo gestaltista. Boletim do Instituto de Psicologia. (3-4), 1-7.

Campos, N. (1955). Algumas considerações sôbre a psicologia científica do pensamento. Boletim do Instituto de Psicologia, (Separata). 3(8-9), 1-15.

Centofanti, R. (1982). Radecki e a Psicologia no Brasil. Psicologia: Ciência e Profissão, 3(1), 2-50. doi: 10.1590/S1414-98931982000100001

Ciência e Cultura: Nilton Campos na Academia de Medicina. (1961, Outubro 7). O Globo, pp. 7.

Cruz, R. N. (2016). Biografia científica e pesquisa teórica da historiografia da psicologia. In C. Laurenti, C. E. Lopes, \& S. F. Araujo (Orgs.). Pesquisa Teórica em Psicologia: Aspectos Filosóficos e Metodológicos (pp. 147-165). São Paulo: Hogrefe.

Cursos: Instituto Brasileiro de Filosofia (Seção do D. F.). (1956, Abril 2). O Globo, pp. 10.

Ensino: Curso de Formação de Psicotécnicos. (1958, Abril 1). Correio da Manhã, pp. 4.

Ensino. (1963a, Setembro 12). Correio da Manhã, pp. 8.

Ensino: Faleceu o Prof. Nilton Campos. (1963b, Setembro 10). Correio da Manhã, pp. 10. 
Esch, C. F., \& Jacó-Vilela, A. M. (2012). A regulamentação da profissão e os currículos de formação psi. In A. M. Jacó-Vilela, A. C. Cerezzo, \& H. B. C. Rodrigues (Orgs.), Clio-Psyché hoje: Fazeres e dizeres psi na história do Brasil (pp. 03-12). Rio de Janeiro: Relume Dumará, FAPERJ. Recuperado de https://static.scielo.org/scielobooks/hkyyb/pdf/jaco-9788579820618.pdf

Féres-Carneiro, T. (2011). Departamento de Psicologia da Pontifícia Universidade Católica do Rio de Janeiro (PUC-Rio): 1967. In A. M. Jacó-Vilela. (Org.), Dicionário histórico de instituições de psicologia no Brasil (pp. 147-148). Rio de Janeiro: Imago

Guimarães, A. C. (1981). A Fenomenologia no Brasil: A Obra de Nilton Campos. In A. C. Guimarães, Momentos do Pensamento Luso-brasileiro (pp. 87-96). Rio de Janeiro: Tempo Brasileiro.

Holanda, A. F. (2012). O método fenomenológico em psicologia: Uma leitura de Nilton Campos. Estudos e Pesquisas em Psicologia, 12(3), 833-851. Recuperado de http://pepsic.bvsalud.org/scielo.php?script=sci_arttext\&pid=S1808$42812012000300007 \& \operatorname{lng}=p t \& t \operatorname{lng}=p t$

Jacó-Vilela, A. M. (2012). História da Psicologia no Brasil: Uma narrativa por meio de seu ensino. Psicologia: Ciência e Profissão. 32(esp.), 28-43. doi: 10.1590/S141498932012000500004

Lobo, F. S. (1953, Junho 05). Abaixo o Charlatanismo: Perigo das más interpretações: Curso de Formação de Psicólogos, regulamentação da profissão: Nova sede para o I. P. Correio da Manhã, pp. 01.

Mancebo, D. (2008). Formação em psicologia: Gênese e primeiros desenvolvimentos. In A. M. Jacó-Vilela (Org.), Clio-Psyché: Histórias da Psicologia no Brasil (pp. 54-71). Rio de Janeiro: UERJ. Recuperado de http://grupodetrabalhoeorientacao.com.br/Virginia_Fontes/capitulos-livros/Clio-ePsyche.pdf

Martins, H. V. (2008). Uma revolução e um revolucionário? A Psicologia na época de Mira y Lopez. In A. M. Jacó-Vilela. (Org.), Clio-Psyché: Histórias da Psicologia no Brasil (pp. 179-183). Rio de Janeiro: UERJ. Recuperado de http://grupodetrabalhoeorientacao.com.br/Virginia_Fontes/capitulos-livros/Clio-ePsyche.pdf

Massimi, M. (1990). História da psicologia brasileira: Da época colonial até 1934. São Paulo: EPU. 
Moraes Filho, E. (1956, Junho). O Homem e o mundo: Filosofia e liberdade de pensamento. A Cigarra, 6, pp. 47.

Penna, A. G. (1992). História da Psicologia no Rio de Janeiro. Rio de Janeiro: Imago.

Penna, A. G. (2008). Breve contribuição à história da Psicologia aplicada ao trabalho, no Rio de Janeiro. In A. M. Jacó-Vilela (Org.), Clio-Psyché: Histórias da Psicologia no Brasil (pp. 135-139). Rio de Janeiro: UERJ. Recuperado de http://grupodetrabalhoeorientacao.com.br/Virginia_Fontes/capitulos-livros/Clio-e-

Psyche.pdf

\section{Endereço para correspondência}

Diego do Nascimento Mendonça

Universidade Federal do Paraná

Departamento de Psicologia

Praça Santos Andrade, s/n, $2^{\circ}$ andar, sala 215, Curitiba - PR, Brasil. CEP 80020-310

Endereço eletrônico: diegomendonca2105@gmail.com / diegonm.psi@ hotmail.com

\section{Adriano Furtado Holanda}

Universidade Federal do Paraná

Departamento de Psicologia

Praça Santos Andrade, s/n, $2^{\circ}$ andar, sala 215, Curitiba - PR, Brasil. CEP 80020-310

Endereço eletrônico: aholanda@yahoo.com

Recebido em: 22/01/2020

Reformulado em: 17/04/2020

Aceito em: $18 / 06 / 2020$

\section{Notas}

* Psicólogo. Bacharel em Psicologia pela Universidade Federal do Ceará e Mestre em Psicologia Clínica pela Universidade Federal do Paraná.

** Psicólogo. Mestre em Psicologia Clínica pela UnB e Doutor em Psicologia pela PUC-Campinas. Professor da Universidade Federal do Paraná.

Agradecimento: aos familiares do Professor Nilton Campos, pelo apoio à pesquisa através do compartilhamento de informações relativas ao psiquiatra carioca.

Este artigo de revista Estudos e Pesquisas em Psicologia é licenciado sob uma Licença Creative Commons Atribuição-Não Comercial 3.0 Não Adaptada. 